\title{
GERONTECHNOLOGY - THE ASSESSMENT OF ONE SELECTED TECHNOLOGY IMPROVING THE QUALITY OF LIFE OF OLDER ADULTS
}

pages: $43-51$

\author{
KATARZYNA HALICKA
}

\begin{abstract}
A B S T R A C T
Older adults experience difficulties in their daily lives as their health deteriorates. Gerontechnology (the compilation of terms "gerontology" and "technology") helps in the resolution of problems faced by older adults by improving their quality of life and, above all, developing tools to facilitate the access of older adults to all goods, services and infrastructure, which is also the understanding of the term used in this paper. The article mainly aimed to assess the selected gerontechnology that improved the quality of life of older adults in terms of different criteria, namely, innovation, demand, socioethics, usability, and functionality. It also analysed whether the respondent's age and gender had any influence on the assessment. Care robots were chosen from among the variety of gerontechnologies. The survey was conducted in the first quarter of 2018 and involved 643 people from different voivodships of Poland. Two types of questionnaires were designed. The electronic form of the survey was distributed using social media and snowball techniques, and the paper form was sent by traditional post to all nursing homes in Poland.
\end{abstract}

KEY WORDS

technology assessment, gerontechnology, humanoid robots, older adults

DOI: 10.2478/emj-2019-0010
Corresponding author:

Katarzyna Halicka

Bialystok University of Technology, Poland e-mail: k.halicka@pb.edu.pl

\section{INTRODUCTION}

At the turn of the 19th and 20th centuries, the average life expectancy barely exceeded 40 years. The percentage of older adults in the total population was minor and equalled $4-6 \%$ of people over 60 years of age (Antoszkiewicz, 2014). For several years now, Poland has been faced with the problem of an ageing society. In Poland, the total population is declining, and the percentage of older adults is growing. According to the Central Statistical Office of Poland (GUS), in 2017, Poland had 6520247 people over 65 years of age. It is forecasted that in 2050, this number will almost double and reach 11097 488. The analysis of the Polish demographic structure in terms of age demonstrates that in 2017, older adults constituted $17 \%$ of the total population. The Central Statistical 
Office of Poland reports that this percentage will be 32.7\% in 2050 (United Nations, 2017), which means that one in three Poles will have reached the retirement age. In the current policy, the Polish government gives a serious priority to many initiatives supporting older adults. One of them was responsible for the founding of the Department of Senior Policy at the Ministry of Labour and Social Policy in 2012. The Department focuses on the needs of the older population while creating and developing guidelines, creating conditions for improving the system of support, executing tasks in the area of active ageing and other forms of cooperation as well as monitoring the implemented solutions (website of the Department of Senior Policy). Moreover, in 2014, the government published the document entitled Long-term Senior Policy in Poland for 2014-2020, which included a number of measures aimed at improving the situation of older adults to ensure dignified ageing in good health. Recognising the issue of the ageing society, the government also published the Government Programme for Social Participation of Senior Citizens for 2014-2020. The document lists support areas and directions that foster the achievement of the major objective, namely, improving the quality and level of life of older adults in terms of dignified ageing by means of social activity.

It should be remembered that the increase in the number of older adults is also associated with the need to provide them with institutional support in the form of care, especially in the case of a low level of independence (Polak-Sopinska, 2015). The increasing life expectancy and ageing will also stimulate changes in a family model. A significant part of older people will live separately, often away from their family, and depend on themselves. Lonely people will need full geriatric care offered at home and nursing homes (Ejdys, 2016). It is important, however, to improve the well-being of the society as well as meet the needs of older adults and use their potential. Several researchers focused on exploring new methods to improve the quality of life of older adults and meet their needs by allowing them to remain independent and healthy to the maximum possible extent.

\section{LITERATURE REVIEW}

One of the fields aiming to find answers to the challenges of the population ageing is gerontechnology - an interdisciplinary field of scientific research that uses technology for the aspirations and opportu- nities of older adults. Gerontechnology is the answer to the needs of older adults concerning their personal development, self-esteem, belonging (which is the main problem due to a drastically reduced number of contacts that causes loneliness), realisation of life plans, adaptation to changing environmental conditions, social expectations, as well as personal capabilities. Gerontechnology is the science of technology and ageing aimed at the improvement of the daily lives of older adults (Graafmans, Taipale \& Charness, 1998). In the narrow sense, gerontechnology means technologies that facilitate the access of older adults to all goods, services and infrastructure (Bronswijk et al., 2009). This paper uses a definition of gerontechnology understood as technologies improving the quality of life of older adults and facilitating access to all goods, services and infrastructure for older adults (Bronswijk et al., 2009; Burdick, 2007). Among other things, gerontechnology should enable older adults:

- to prevent problems,

- to increase self-reliance without changing skills and environment,

- to compensate for the loss of options if the facilities are unable to provide them,

- to provide the service only if needed,

- to streamline the existing projects.

In the global literature, research on gerontology focuses on the following issues: (i) analyses of application areas of different gerontological technologies such as health and self-esteem, housing and daily life, mobility and transport, communication and management, work and leisure; the International Society for Gerontechnology); (ii) studies of the attitudes and experiences of older people towards the use of gerontological technologies and the identification of causes that may form the basis for their use or rejection (Chen \& Chan, 2013): (iii) technology analysis for four categories of older people's needs: social, medical, activeness and safety (Fozard et al., 2000); (iv) the impact of gerontology on the physical, mental health and social functions of its users (Fozard, 2000; Khosravi et al., 2016; Prada et al., 2018; Fraile et al., 2014; Frisardi \& Imbimbo, 2011; Usman et al., 2013; Koops et al., 2013; Piezzo \& Suzuki, 2017).

In the Polish literature, gerontology research is causal and most often reproducible based on foreign research results. Wieczorek (2016), for example, reviewed two types of robots used in the care for older adults: assistive robots that were not social robots (e.g. intelligent wheelchairs) and social robots communicating with the user, pointing to examples of their use. Boruta (2017) indicated gerontechnolo- 
gies as one of the tools for satisfying the housing needs of older people, pointing to the possibility of housing improvements based on the example of model housing for older adults in Warsaw's Bielany (Boruta, 2017). At the same time, the author concluded that the large diversity of needs and expectations of older adults creates the possibility to generate various technological solutions that adequately satisfy these needs. Similarly, Rzeczyński analysed gerontechnologies from an urban perspective (Rzeczyński, 2009). Comparable issues were addressed by Giezek and Iwański, who presented a concept of organising protected and assisted housing for older people requiring support and assistance in everyday life (Giezek \& Iwański, 2017).

In order for such technologies to be marketed and used, it is necessary to identify the priority attributes required from technologies that facilitate ageing. These technologies must be assessed in the light of criteria such as their functionality, competitiveness, innovation and socio-ethical aspects. To date, no studies have been carried out in Poland to assess technologies that improve the quality of life of older adults, considering various criteria. No studies have been carried out to check whether age and gender have an impact on the assessment of gerontechnology. The main areas of gerontechnology were, among others, as follow (Obia, Ishmatovab \& Iwasakic 2013):

- technologies supporting the functioning of older adults,

- technologies accompanying older adults,

- emotions/mastery over them/recognition and mood regulation,

- personalised adaptation of the environment,

- social/caring cognitive robots and agents,

- technologies guaranteeing entertainment for older adults,

- smart telehealth, telemedicine and communication services,

- social networks for older adults.

This paper presents the results of the assessment, depending on the age and gender of the respondent, of one gerontechnology, namely, social/supporting humanoid robots used in the care for older people.

Robots can be used by older adults to capture, transmit, recall information related to the use of medication, recognise and assess health, monitor and motivate walking, and meet social needs through interaction (Broadbent et al., 2009; Broekens et al., 2009; Ejdys \& Gdvilaite, 2017; Flandorfer, 2012; Grant et al., 2004; Piezzo \& Suzuki, 2017). Given the technological potential of robots and the rate of the ageing of the population in the near future, robots may start being used for helping people to care for older adults and offer some company for this group of the population (Ejdys \& Halicka, 2018; Choi et al., 2014; Klamer \& Allouch, 2010; Martinez-Martin \& del Pobil, 2018; Pollack et al., 2002; Usman \& Tomimoto, 2013). The literature studies and exploratory research conducted so far allow the following research questions to be formulated:

- How the technology has been assessed against different criteria?

- Does age influence the assessment of humanoid robot technologies used in the care for older adults?

- Does gender influence the assessment of humanoid robot technologies used in the care for older adults?

\section{RESEARCH METHODS}

Based on the literature review, five groups of technology assessment criteria were selected: innovation, demand, socio-ethics, usability, and functionality (Ejdys, 2015; Nazarko et al., 2015; Radziszewski et al., 2016). The criteria were formulated in the form of statements. The authors prepared the catalogue of criteria consisting of 27 statements, which included seven concerned marketing aspects (D1-I D7) and five of each of the following: technology innovation (I1-I5), socio-ethical aspects (S1-S5), usability (U1-U5) and technology functionality (F1-F5). To assess the technology, questionnaire surveys were used. The research was conducted on a sample of 643 Poles between March and April 2018. The respondents represented all the voivodships of Poland. The respondents evaluated the assessment of the analysed technology using the 7-point Likert scale, where 1 meant "it definitely means I do not agree with the given statement" and 7 - "I definitely agree." Considering the fact that not all respondents were familiar with the concept of a humanoid robot, it was replaced with the term "robot" in the questionnaire. In the sample structure, $32.7 \%$ (210) of people were aged $18-25,24.9 \%$ (160) were $26-40,25.8 \%$ (166) were 41-60 and $16.4 \%$ (107) were over 60 . All in all, $42 \%$ (270) respondents were men, and 58\% (373) were women.

Initially, the respondents assessed the technology in terms of such criteria as innovation, demand, socio-ethics, usability, and functionality (step I). 
It was further examined whether the age and gender of respondents influenced the assessment of the humanoid robots used for the care of the older adults in terms of demand and the socio-ethical aspect (step II). The level of demand for this technology was verified using seven statements (Halicka, 2017; Nazarko, 2017): D1: On the part of older adults, there is a need for care robots supporting the older adults; D2: On the part of family members, there is a need for care robots supporting the older adults; D3: On the part of institutions responsible for the care of the older adults (e.g. nursing homes), there is a need for care robots supporting the older adults; D4: The use of robots for the care of the older adults will be a source of additional benefits for their users (24-hour attendance, 24-hour care, a sense of security), which are unavailable through other solutions; D5: The global demand for care robots supporting the older adults is associated with temporary fashion; D6: Using a robot to care for an older adult will not require new, specialist knowledge; D7: The robot's appearance will have a significant impact on the scale of its use in everyday life. In turn, in socio-ethical terms, this technology was evaluated using the following five statements: S1: The widespread use of robots in the care of the older adults will bring measurable social benefits; S2: The widespread use of robots in the care of the older adults will create new jobs; S3: The widespread use of robots in the care of the older adults will bring measurable benefits to human health and the quality of human life; S4: The widespread use of robots in the care of the older adults can be a source of social problems; S5: The widespread use of robots in the care of the older adults can be the cause of moral dilemmas and doubts as to whether robots can be entrusted with the care for the older adults.

\section{RESEARCH RESULTS}

Firstly, the respondents rated the technology in terms of its innovativeness. Then, the respondents assessed the technology in terms of demand. The respondents also made a technology assessment in terms of socio-ethical aspects and usability. Then, average scores of technologies of personal care robots for older adults in terms of the innovation criterion, demand, socio-ethical aspects, usability and functionality were calculated based on individual data (Fig. 1).

According to Fig. 1, the technology was ranked the best in terms of its functionality. The average assessment of respondent compliance with claims regarding the functionality of the technology was 5.82 (on a scale from 1 to 7 ). On the other hand, the average assessment of respondent compliance with statements regarding innovation amounted to 4.87 . Respondents also highly rated the technology of personal care robots for older adults in terms of demand. The average of respondent compliance assessments with this regarding the above-mentioned criteria was 4.57. In turn, the lowest score was given to the technology in terms of socio-ethical aspects. The average assessment of respondent compliance with statements regarding socio-ethical aspects was 3.69.

Next, it was checked whether the age and gender of respondents influenced the technology assessment.

A critical significance level was assumed at $\mathrm{p}=0.1$. The non-parametric Mann-Whitney $\mathrm{U}$ test (Wilcoxon, 1945; Mann \& Whitney, 1947) was used to study the effect of gender on the technology assessment. In turn, the ANOVA Kruskal-Wallis test was used to examine the influence of age on technology assessment. The Statistica 13 software was used in the research.

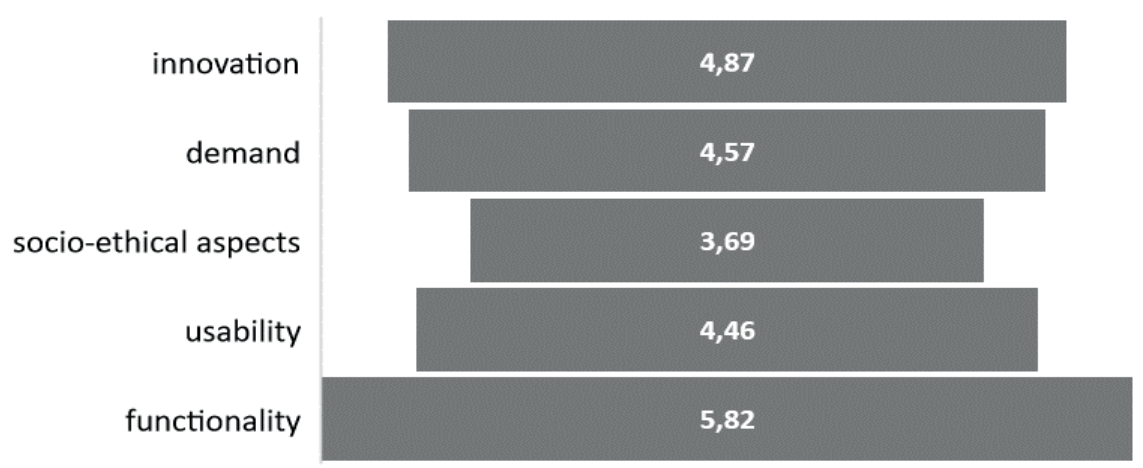

Fig. 1. Collective assessment of the technology of personal care robots for older adults in terms of the innovation criterion, demand, socio-ethical aspects, usability and functionality 
Tab. 1. Values of statistics for technology assessment of personal care robots for older adults in terms of demand

\begin{tabular}{|c|c|c|c|c|}
\hline \multirow[t]{2}{*}{ ACRONYM } & \multicolumn{2}{|c|}{ Statistics Of the MANN-Whitney U test } & \multicolumn{2}{|c|}{$\begin{array}{l}\text { STATISTICS OF THE ANOVA KRUSKAL-WALLIS } \\
\text { TEST }\end{array}$} \\
\hline & $\mathbf{U}$ & $\mathbf{P}$ & $\mathbf{T}$ & $\mathbf{P}$ \\
\hline D1 & 47108.00 & 0.162578633 & 11.18819 & 0.0108 \\
\hline D2 & 48041.00 & 0.319672595 & 12.73677 & 0.0052 \\
\hline D3 & 49822.50 & 0.818997074 & 4.385920 & 0.2227 \\
\hline D4 & 49117.50 & 0.594667432 & 3.812452 & 0.2824 \\
\hline D5 & 49203.50 & 0.620534872 & 7.994963 & 0.0461 \\
\hline D6 & 44379.50 & 0.0101674892 & 3.775917 & 0.2867 \\
\hline D7 & 44966.00 & 0.0204598559 & 19.69931 & 0.0002 \\
\hline
\end{tabular}

Tab. 2. Values of statistics for the technology assessment of personal care robots for older adults in terms of socio-ethical aspects

\begin{tabular}{|c|r|r|r|r|}
\hline \multirow{2}{*}{ ACRONYM } & \multicolumn{2}{|c|}{ StATISTICS OF THE MANN-WhITNEY U TEST } & \multicolumn{2}{c|}{ StATISTICS OF THE ANOVA KRUSKAL-WALLIS } \\
\cline { 2 - 5 } & U & P & T & T \\
\hline S1 & 47890.5 & 0.289205106 & 7.925149 & 0.0476 \\
\hline S2 & 45829.5 & 0.051608717 & 9.091852 & 0.0281 \\
\hline S3 & 45462.00 & 0.035338459 & 11.10373 & 0.0112 \\
\hline S4 & 48663.5 & 0.467000255 & 2.767013 & 0.4290 \\
\hline S5 & 50338.5 & 0.994508795 & 2.094907 & 0.5529 \\
\hline
\end{tabular}

Initially, the respondents assessed the demand for technologies. The values of statistics for technology assessment in terms of demand are presented in Tab. 1.

Analysing Tab. 1, it can be noticed that the significant gender differences in the assessment of the level of demand for personal care robots for older adults $(p<0.1)$ only occur in the case of statements D6 and D7. According to Tab. 1, statistically significant differences depending on the age occur in the case of acceptance of drivers D1, D2, D5 and D7 $(p<0.1)$. In the case of other statements, no significant differences were observed between the assessment of these statements and age.

The respondents also assessed the technology in terms of socio-ethical aspects (Tab. 2).

Analysing Tab. 2, statistically significant differences in relation to gender in the assessment of this technology in terms of social-ethical aspects occur in the case of assessing statements S2 and S3 ( $p<0.1)$. However, statistically significant differences depending on age occur in the case of acceptance of statements S1, S2 and S3 ( $p<0.1)$. In the case of other statements, no significant differences were observed between the assessment of these statements and age.

\section{DISCUSSION OF THE RESULTS}

Detailed analysis of the responses in the context of the demand for technology revealed that men found the appearance of a robot more important than women (D7). The average value of answers for men was 5.3 while it amounted to 4.9 for women (Fig. 2). There were also different opinions - depending on the sex - in the assessment of the statement D6: Using a robot to care for an older adult. The average value of answers was 3.8 for men and 3.3 for women.

Fig. 3 graphically illustrates the values of the acceptance response of selected statements (statistically significant) regarding the technology assessment of personal care robots for older adults in terms of demand in four age groups.

The analysis of Fig. 3 revealed the smallest acceptance of the D1 statement occurring among respondents aged 41-60 (the average score of 3.3), and the largest among the participants aged 26-40 (the average assessment of the D1 statement amounting to 4.1). On the other hand, the D2 statement had the lowest acceptance among people over 60 (the average grade of 4.3), and the largest among the youngest participants of the study (the average grade of 5.3). In the case of people aged 18-25 and 41-60, the accep- 

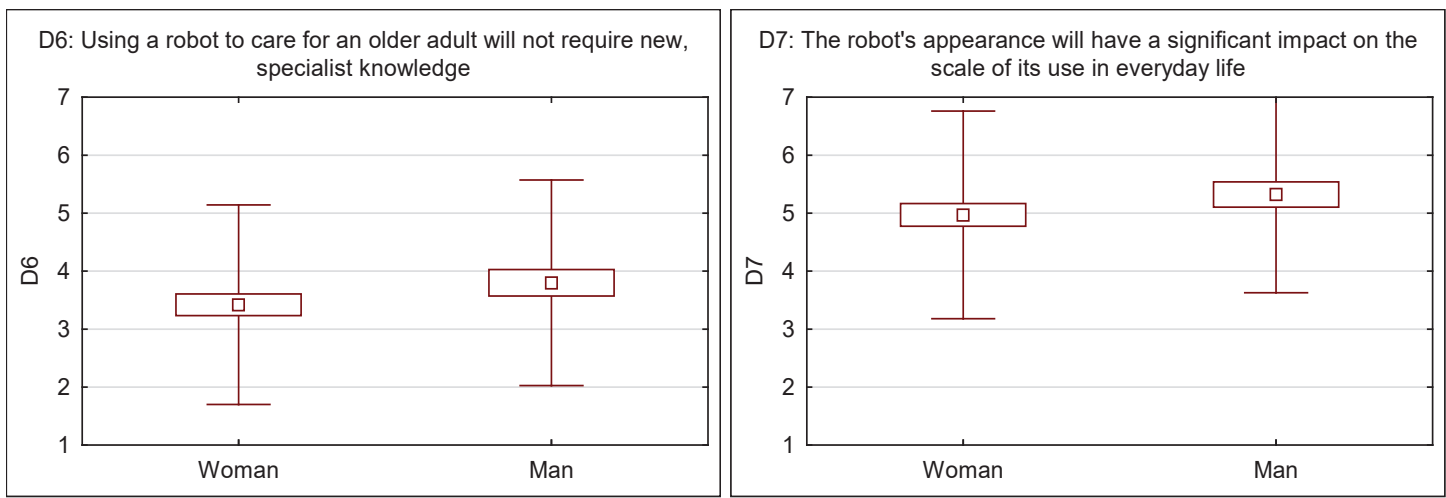

Fig. 2. Technology assessment of personal care robots for older adults in terms of demand in gender groups - selected answers

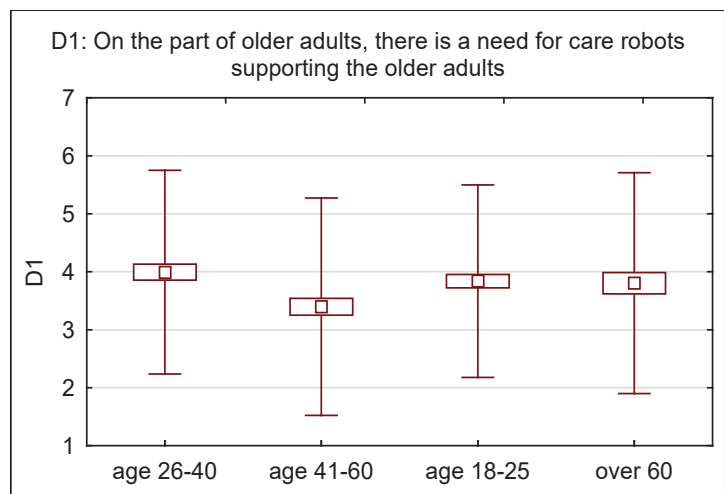

D5: The global demand for care robots supporting the older adults is associated with temporary fashion

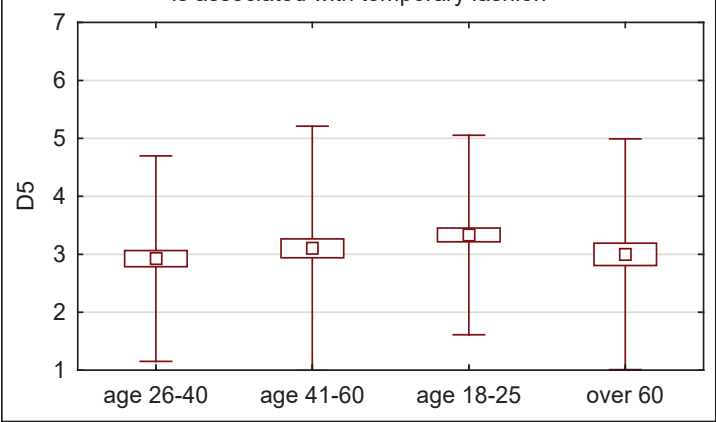

D2: On the part of family members, there is a need for care robots supporting the older adults

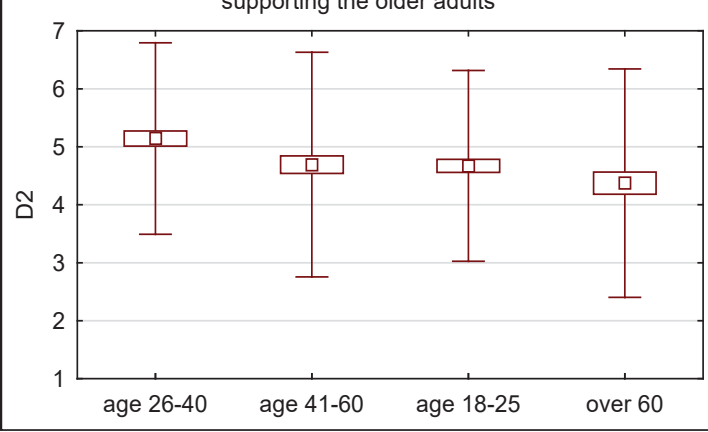

D7: The robot's appearance will have a significant impact on the scale of its use in everyday life

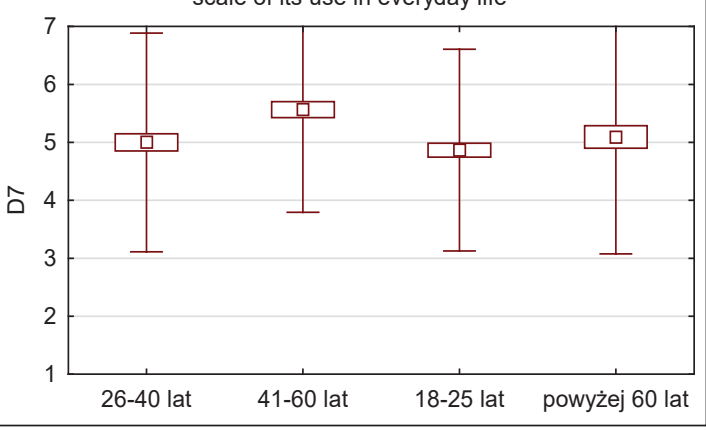

Fig. 3. Technology assessment of personal care robots for older adults in terms of demand in four age groups - selected answers

tance of this statement was similar (the average grade of 4.7). The D5 statement enjoyed the highest acceptance among people aged 18-25 (the average grade of 3.4). The lowest assessment was given by respondents of 26-40 (the average grade of 2.8). In turn, the D7 statement was rated the lowest by the youngest respondents (the average grade of 4.8), and the highest by respondents aged 41-60 (the average grade of 5.6).

On the other hand, analysing the responses regarding the assessment of technology in terms of social-ethical aspects, it was noticed that the acceptance of S2 was greater among men than women: the widespread use of robots in the care of the older adults would contribute to the creation of new jobs (the average assessment for S2 was 3.4 for men and 3.1 for women). The average score for the S3 statement (The widespread use of robots in the care of the older adults will bring measurable benefits to human health and the quality of human life) was also statistically significant and amounted to 4.7 for men and 4.2 for women (Fig. 4).

Fig. 5 graphically illustrates the response values for the socio-ethical aspects in four age groups. The analysis of Fig. 5 showed that the smallest acceptance of S1 was found among respondents aged 18-25 (the 


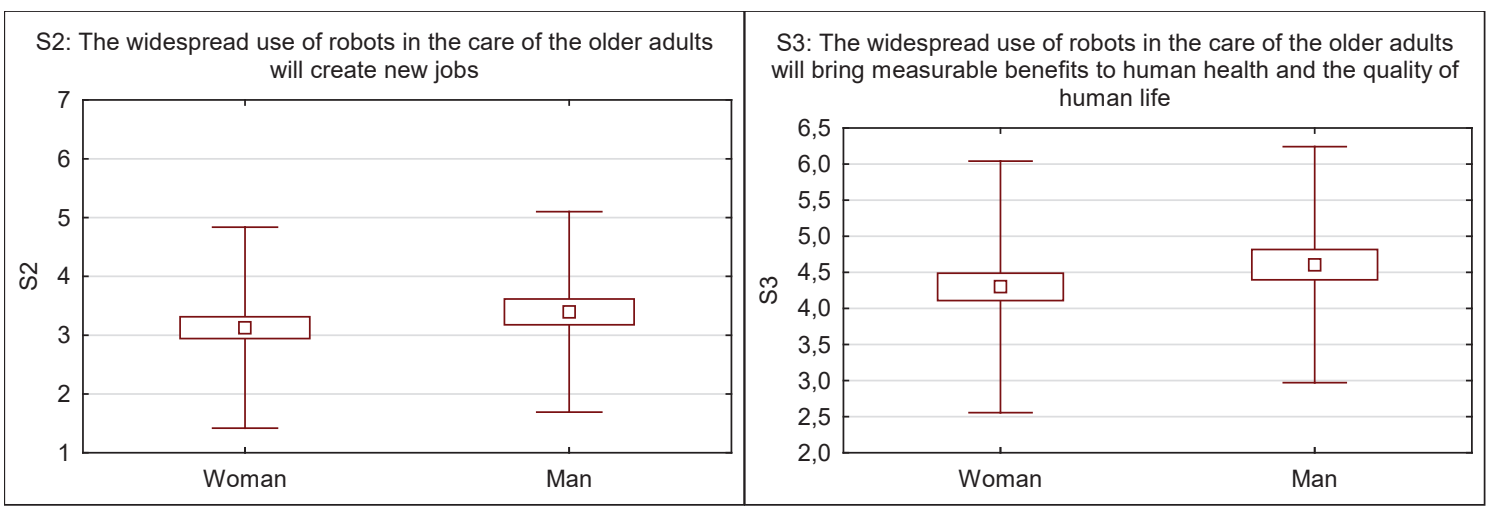

Fig. 4. Technology assessment of personal care robots for older adults in terms of socio-ethical aspects in gender groups - selected answers

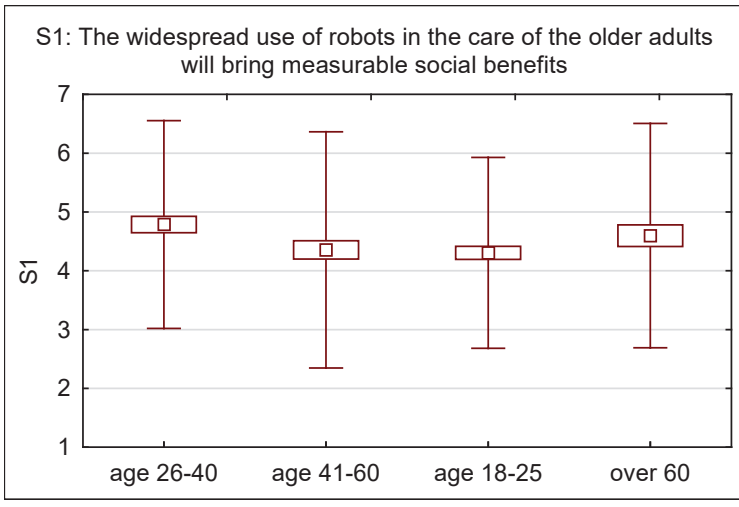

S2: The widespread use of robots in the care of the older adults will create new jobs

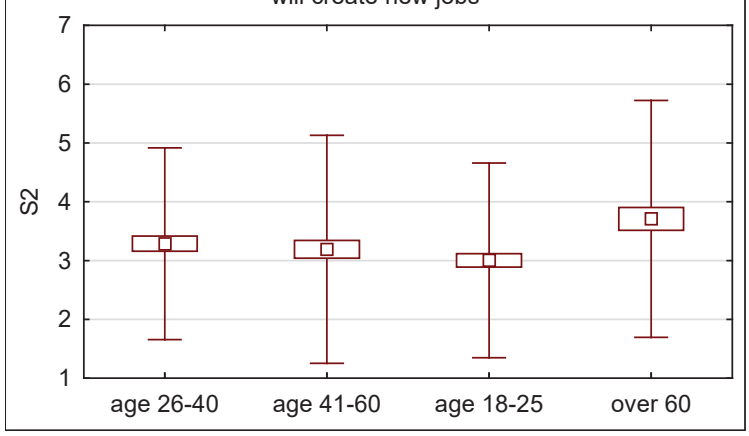

S3: The widespread use of robots in the care of the older adults will bring measurable benefits to human health and the quality of human life

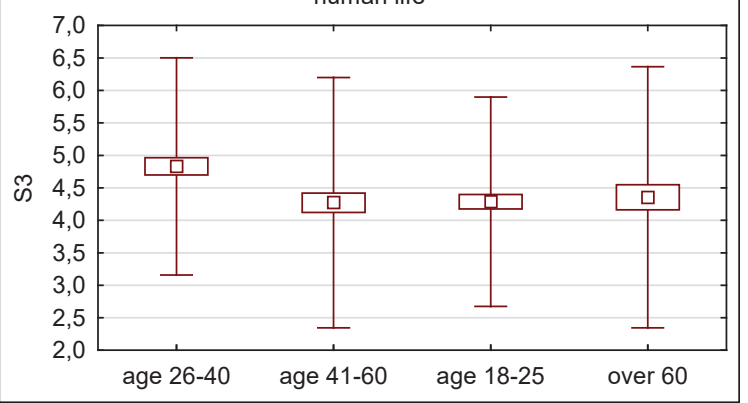

Fig. 5. Technology assessment of personal care robots for older adults in terms of socio-ethical aspects in four age groups selected answers

average grade of 4.3) and 41-60 (the average grade of 4.3), while it was the largest among participants aged 26-40 (the average grade of the S1 statement amounting to 4.9). On the other hand, the S2 statement enjoyed the highest acceptance among people over 60 (the average grade of 3.8), even though it was the lowest among the youngest participants of the study (the average grade of 3.0). Statement S3 had the highest acceptance among people aged $26-40$ (the average grade of 4.9). It received the lowest assessment from respondents aged 41-60 (the average grade of 2.9) and $18-25$.

\section{CONCLUSIONS}

This article assesses technologies of personal care robots for older adults in different terms. The main premise of the research was searching for answers to the following questions: (1) How the technology has been assessed against different criteria? (2) Does age influence the assessment of humanoid robotic technologies used in the care for older adults? (3) Does gender influence the assessment of humanoid robotic technologies used in the care for older adults? 
Based on the conducted research, it can be concluded that the technology of personal care robots for older adults has been rated the highest in terms of functionality. This technology was also highly rated in terms of innovativeness and demand. The lowest score was given for this technology in terms of socioethical aspects. Considering the average values of the survey results, it should be stated that the assessment of this technology in terms of demand as well as socio-ethical aspects is influenced by the age and gender of respondents. A conclusion can be made with a probability of $90 \%$ that the gender of a respondent influences the assessment of technology in terms of technology demand and socio-ethical aspects. The results of the research also allow making an observation with the same probability of $90 \%$ that the age of a respondent influences the assessment of technology in terms of socio-ethical aspects.

The results of the research tasks described in this article can be used as a knowledge base for the development of technology cards of humanoids used in the care for the older adults. In the cards, it is possible to collect and organise the most important information regarding the analysed technology, improving the quality of life of older adults.

Further scientific activities will include research efforts into the preparation of technology development paths that improve the quality of life of older adults. Various aspects will be considered, including usability, functionality and trust. In addition, other gerontechnologies will be identified and assessed in further research. A ranking of the best gerontechnologies will then be developed using-multi attribute decision-making methods.

\section{ACKNOWLEDGEMENTS}

The research was conducted within the scope of the project S/WZ/1/2017 and financed from the funds of the Ministry of Science and Higher Education.

\section{LITERATURE}

Antoszkiewicz, J. D. (2014). Starzenie się społeczeństwa a zagadnienia edukacyjne [Ageing and educational issues]. Przedsiębiorczość i Zarządzanie, XV(11), 9-20.

Boruta, M. (2017). Gerontechnologia jako narzędzie w procesie zaspokajania potrzeb mieszkaniowych [Gerontechnology as a tool in the process of satisfying housing needs]. Progress in Economic Sciences, 4, 25-36.
Broadbent, E., Stafford, R., \& MacDonald, B. (2009). Acceptance of Healthcare Robots for the Older Population: Review and Future Directions. International Journal of Social Robotics, 1, 319-330. doi:10.1007/ s12369-009-0030-6

Bronswijk, J. E. M. H. et al. (2009). Defining Gerontology for R\&D Purposes, Gerontechnology, 8(1), 3-10, doi: 10.4017/gt.2009.08.01.002.00

Burdick, D.C. (2007). Gerontechnology. In Birren, J. E. (Ed.), Encyclopedia of Gerontology: Age, aging, and the aged (pp. 619-630). Oxford, England: Academic Press.

Chen, K., \& Chan, A. H. (2013). Use or Non-Use of Gerontechnology - A Qualitative Study. International Journal of Environmental Research and Public Health, 10, 4645-4666. doi:10.3390/ijerph10104645

Choi, H., Park, J. O., Ko, S. Y., \& Park, S. (2014). Deflection analysis of a robotic bed on the applied loads and its postures for a heavy-ion therapeutic system. In 9th International Conference on Robotic Vision, Signal Processing and Power Applications (pp. 343-350). Singapore: Springer.

Ejdys, J. (2015). Innovativeness of residential care services in Poland in the context of strategic orientation. Procedia - Social and Behavioral Sciences, 213, 746-752.

Ejdys, J., \& Gedvilaite, D. (2017). Learning orientation in nursing homes in Poland. Engineering Management in Production and Services, 9(3), 51-63.

Ejdys, J., \& Halicka, K. (2018). Sustainable Adaptation of New Technology - The Case of Humanoids Used for the Care of Older Adults. Sustainability, 10(10), 3770. doi:10.3390/su10103770

Flandorfer, P. (2012). Population ageing and socially assistive robots for elderly persons: The importance of sociodemographic factors for user acceptance. International Journal of Population Research, 12, 1-13.

Fozard, J. L. (2005). Gerontechnology: Optimising relationships between people and changing technology. In Minichiello, V., \& Coulson, I. (Eds.), Contemporary Issues in Gerontology: Promoting Positive Ageing. London, United Kingdom: Routledge.

Fraile, J.A. et al. (2014). Contextaware multiagent system: Planning Home Care Tasks. Knowledge and Information Systems, 40(1), 171-203.

Frisardi, V., \& Imbimbo, B. P. (2011). Gerontechnology for Demented Patients: Smart Homes for Smart Aging. Journal of Alzheimer's Disease, 23(1), 143-146. doi: 10.3233/JAD-2010-101599

Giezek, M., \& Iwański, R. (2017). Mieszkania chronione i wspomagane dla osób starszych w ujęciu społecznoekonomicznym [Protected and assisted housing for elderly people from a socio-economic perspective]. Handel Wewnętrzny, 4(1), 287-296.

Graafmans, J. A. M., Taipale, V., \& Charness, N. (Eds.) (1998). Gerontechnology: a sustainable investment in the future, Studies in health technology and informatics. Amsterdam, Netherlands: IOS Press.

Grant, J., Hoorens, S., Sivadasan, S., van het Loo, M., DaVanzo, J., Hale, L., Gibson, S., \& Butz, W. (2004). Low Fertility and Population Ageing: Causes, Consequences, and Policy Options. Santa Monica, United States: RAND. 
Halicka, K. (2017). Main Concepts of Technology Analysis in the Light of the Literature on the Subject. Procedia Engineering, 182, 291-298. doi:10.1016/j.proeng.2017.03.196.

Khosravi, P., Rezvani, A., \& Wiewiora, A. (2016). The impact of technology on older adults' social isolation. Computers in Human Behavior, 63, 594-603.

Klamer, T., \& Ben Allouch, S. (2010). Acceptance and use of a social robot by elderly users in a domestic environment. Presented at the Pervasive Computing Technologies for Healthcare (PervasiveHealth), Munchen, Germany, 22-25 March 2010.

Koops, E. J., Di Carlo, A., Nocco, L., Cassamassima, V., \& Stradella, E. (2013). Robotic technologies and fundamental rights. International Journal of Technoethics, 4, 15-35. doi:10.4018/jte.2013070102

Mann, H. B., \& Whitney, D. R. (1947). On a test of whether one of two random variables is stochastically larger than the other. Annals of Mathematical Statistics, 18, 50-60.

Martinez-Martin, E., del Pobil, A.P. (2018). Personal Robot Assistants for Elderly Care: An Overview. In Costa, A., Julian, V., \& Novais, P. (Eds.), Personal Assistants: Emerging Computational Technologies (pp. 77-91). Cham, Switzerland: Springer.

Nazarko, J., Radziszewski, P., Dębkowska, K., Ejdys, J., Gudanowska, A., Halicka, K., Kilon, J., Kononiuk, A., Kowalski, K., Król, J., Nazarko, Ł., Sarnowski, M., \& Vilutiene, T., (2015). Foresight Study of Road Pavement Technologies. Procedia Engineering, 122, 129136.

Nazarko, Ł., (2017). Future-Oriented Technology Assessment. Procedia Engineering, 182, 504-509. doi:10.1016/j.proeng.2017.03.144.

Obia, T., Ishmatovab, D., \& Iwasakic, N. (2013). Promoting ICT innovations for the ageing population in Japan. International Journal of Medical Informatics, 82, 47262.

Piezzo, Ch., \& Suzuki, K. (2017). Feasibility study of a socially assistive humanoid robot for guiding elderly individuals during walking. Future Internet, 9, 30. doi:10.3390/fi9030030

Pollack, M. E., Brown, L., Colbry, D., Orosz, C., Peintner, B., Ramakrishnan, S., Roy, \& Pearl, N. (2002). A mobile robotic assistant for the elderly. Paper presented at the AAAI Workshop on Automation as Eldercare, Edmonton, AB, Canada.

Prada, G. I., Mihaela Nacu, R., Kozma, A., \& Herghelegiu, A. M. (2018). Gerontechnology - Technology for Older People, Buletin Stiintific, Supplement 3, 117122.

Radziszewski, P., Nazarko, J., Vilutiene, T., Dębkowska, K., Ejdys, J., Gudanowska, A., Halicka, K., Kilon, J., Kononiuk, A., Kowalski, K. J., Król, J. B., Nazarko, Ł., \& Sarnowski, M. (2016). Future trends in road pavement technologies development in the context of environmental protection. The Baltic Journal of Road and Bridge Engineering, 11(2), 160-168.

Rzeczyński, B. (2009) Gerontechnologia w perspektywie urbanistycznej [Gerontechnology from an urban perspective]. Acta Universitatis Lodziensis. Folia Oeconomica, 231, 287-304.
United Nations (2017). World Population Prospects, The 2017 Revision. Retrieved from https://esa.un.org/ unpd/wpp

United Nations, Department of Economic and Social Affairs, Population Division (2017). World Population Prospects: The 2017 Revision. New York, United States: United Nations.

Usman, M., \& Tomimoto, I. (2013). The Aging Population of Japan: Causes, Expected Challenges and Few Possible Recommendations. Research Journal of Recent Sciences, 2, 1-4.

Wieczorek, A. (2016). Gerontechnologia w rozwiązywaniu problemów osób starszych. [Gerontechnology in solving problems of elderly people]. Systemy Wspomagania w Inżynierii Produkcji, 2(14), 358-370.

Wilcoxon, F. (1945). Individual comparisons by ranking methods. Biometrics Bulletin, 1, 80-83. 